\title{
Factors Affecting Parental Mediation Strategies in Children's Technology Use: A Systematic Review
}

\author{
Rabia ÜSTÜNDAĞ ALKAN¹ (D) Alper ASLAN*2 (D) Yiğit Emrah TURGUT² (D) \\ Engin KURŞUN ${ }^{4}$ (D) \\ 1 The Ministry of National Education, Erzincan, Turkey, rb.ustundag@gmail.com \\ ${ }^{2}$ Munzur University, Cemişgezek Vocational High School, Tunceli, Turkey, alperaslan@gmail.com \\ ${ }^{3}$ Recep Tayyip Erdoğan University, Faculty of Education, Rize, Turkey, yigitemrah.turgut@erdogan.edu.tr \\ 4 Atatürk University, Kazım Karabekir Faculty of Education, Erzurum, Turkey, ekursun@atauni.edu.tr \\ * Corresponding Author: alperaslan@gmail.com
}

\begin{tabular}{|c|c|}
\hline Article Info & Abstract \\
\hline $\begin{array}{l}\text { Received: } 22 \text { April } 2021 \\
\text { Accepted: } 29 \text { June } 2021\end{array}$ & $\begin{array}{l}\text { Parents raise their children by using their own social, cultural, and } \\
\text { financial resources. With the development of technology, parents } \\
\text { started guiding their children in digital environments. In other } \\
\text { words, parents attempt to regulate their children's use of media } \\
\text { while maximizing the benefits of media-rich digital environments }\end{array}$ \\
\hline $\begin{array}{l}\text { Keywords: Parents, child, mediation } \\
\text { strategies, technology }\end{array}$ & $\begin{array}{l}\text { for their children. This study aimed to examine, evaluate, and } \\
\text { interpret the factors affecting parental mediation strategies through } \\
\text { meta-synthesis method. A total of } 16 \text { studies were reviewed. The }\end{array}$ \\
\hline doi $10.18009 /$ jcer.925859 & $\begin{array}{l}\text { results revealed that demographic characteristics including age, } \\
\text { gender, educational level, and socio-economic status, use of }\end{array}$ \\
\hline Publication Language: English & $\begin{array}{l}\text { technology, parents' attitudes and perceptions towards technology } \\
\text { are the critical factors influencing parental mediation strategies. }\end{array}$ \\
\hline open 2 access & $\begin{array}{l}\text { To cite this article: Üstündağ-Alkan, R., Aslan, A., Turgut, Y. E., \& } \\
\text { Kurşun, E. (2021). Factors affecting parental mediation strategies in } \\
\text { children's technology use: A systematic review. Journal of Computer } \\
\text { and Education Research, } 9 \text { (18), 702-723. DOI: } 10.18009 / \text { jcer. } 925859\end{array}$ \\
\hline
\end{tabular}

\section{Introduction}

Family as the smallest entity of a society is the basis for culture, societies' perceptions, and many other social structures. Parents raise children based on their social, cultural, and financial resources and contribute to the development of the society. Today, many factors including the increase in digital environments and developments in technology result in digitalization of societies. As a result, parents have the tendency towards raising their children in digital environments as well. Parents' attempt to raise their children based on their perceptions towards children and digital environments is called as digital parental mediation. Livingstone and Helsper (2008) stated that parents manage their children's relation with and perceptions towards media through their mediation activities. Also, Cabello-Hutt et al. (2018) mentioned that parents have the power to influence their children's perceptions towards identifying online situations they encounter as opportunities or dangers. 


\section{Literature Review}

\section{Parental Mediation}

Nikken and Opree (2018) defined parental mediation as all practices parents employ to shape and regulate their children's use of media. Livingstone and Helsper (2008) define parental mediation as the parents' management of their children's relationship with media. Clark (2011) classified parental mediation into four categories: active mediation, restrictive mediation, co-viewing, and participatory learning. While active mediation includes parentchild dialogs, co-viewing consists of non-verbal communication and being with child during media use. The participatory learning enables parents learn from their children. On the other hand, parents with restrictive mediation set rules and follow up the results if rules are broken. On the other hand, Coyne et al. (2017) disagreed with Clark by pointing out interchangeability in parental mediation with time. Dias and Brito (2020) stated that parental mediation is a dynamic process. Similarly, Smahelova et al. (2017) stated that parental mediation is not a fixed behavior and management and various mediation strategies may be used at the same time depending on some factors. The researchers also discussed that mediation strategies are shaped by parents and children together.

\section{Factors Affecting Parental Mediation}

There exist some factors that influence parents' mediation strategies. Those factors are parental factors including their education level and internet usage level (Cabello-Hutt et al., 2018), age of the child (Darga, 2021; Livingstone \& Helsper, 2008), the relationship between the parents and the child especially in adolescence (Smahel \& Wright, 2014), parents' technology usage competencies (İnan-Kaya et al., 2018), parents' socio-economic situations, and their perceptions towards technology (Darga, 2021; Nikken \& Opree, 2018). On the other hand, there are also studies reporting the details of those factors and their effects or stating that they are ineffective. Although Smahel and Wright (2014) revealed that parent-child relationship is an effective factor in children's problematic internet usage, Chen et al. (2015) revealed a negative association between parent-child relation and adolescents' problematic Internet usage. Also, in another study, it is stated that the relationship with peers and the peer environment are extremely important as much as family communication. These results imply that parental mediation in children's Internet usage is and will be an ongoing debate in the literature. 
Importance of the Study

Parental attitudes are critical while raising a child. Specifically, parents' attitudes, communication styles, and behaviors in childhood and adolescence significantly affect child's adulthood (Yıldırım, 2018). Parental attitudes towards digital media and interactions within the family are directly related to the development of individuals and society. Livingstone et al. (2017) stated that society relies on parents in terms of children's readiness to changes due to education and technology and prevention of children from online risks. Therefore, it is critical to examine parental mediation strategies. Investigation of factors influencing parental mediation strategies may improve and guide parents' strategies to manage their children's use of media. As parents determine the mediation strategies through trial and error (Smahelova et al., 2017), both parents and children encounter some issues when children experience online risks. Therefore, there is a strong need to examine the factors affecting parental mediation strategies, which enables researchers to observe the change in parents' mediation strategies and difficulties children encounter (Young \& Tully, 2019). Nathanson (2015) reported studies focusing on how parents direct their children in terms of children's experiences in digital environments. On the other hand, Van Petegem et al. (2019) mentioned a limited number of studies examining the changes in mediation strategies based on some demographic variables. When the literature is reviewed, the researchers did not come up with a study in which the factors affecting the parents' mediation strategies are examined as a whole. Therefore, this study aims to systematically examine the studies in the literature to determine the factors affecting parental mediation strategies, which will shed a light on the improvement and guidance of those strategies.

\section{Method}

\section{Research Model}

Since this study aimed to examine, evaluate, and interpret the factors affecting parental mediation strategies, a meta-synthesis approach was conducted. Zimmer (2006) defines a meta-synthesis approach as one of the qualitative study that uses the findings of other studies as data. Meta-synthesis studies aim to interpret and evaluate qualitative findings of studies conducted in a specific field, to reveal similarities and differences, and to make new inferences (Polat \& Ay, 2016). More specifically, meta-synthesis is based on the 
interpretive analysis of qualitative findings of studies rather than an ordinary analysis of research (Aspfors \& Fransson, 2015). In meta-synthesis studies, the optimum number of studies to be examined is ten since a larger number of samples tend to hinder in-depth analysis (Sandelowski, Docherty \& Emden, 1997).

Procedures of Meta-Synthesis

In this study, the following steps suggested by Polat and Ay (2016) were followed:

(1) Determining the purpose of the study

(2) Finding studies suitable for the purpose of the study

(a) Determining databases to be searched

(b) Identifying keywords

(c) Screening and removing duplicate studies

(3) Selecting studies

(a) Naming possible studies (Possible Study1 [PS1])

(b) Determining the inclusion and exclusion criteria

(c) First round review in terms of the titles and abstracts

(d) Second round review in terms of all sections of the studies

(e) Excluding unrelated studies and re-naming the included studies (Study1 [S1])

(4) Coding and creating themes (determining the factors examined in studies)

(a) Pilot coding by researchers

(b) Creating the code and theme maps

(c) Coding and creating themes

(d) Finalizing the codes and themes

(e) Synthesizing the obtained themes

(f) Reporting the research process and findings

\section{Data Collection and Analysis}

During the data collection and analysis process, the above-mentioned steps were followed. First, the purpose of the study was identified. Then, studies related to the purpose were identified. 
Identification of the Studies

In order to identify studies suitable for the purpose of the current study, keywords and databases were determined. Both Web of Science and ERIC databases were used for searching studies since Web of Science can provide access to many libraries and journals and ERIC includes education-related studies. During the review of the studies, the following keyword was used for both databases: "digital parents and parental mediation." Since the first round review was carried out in February 2020, the studies published until this date were searched by considering the title, abstract and keywords. All review and experimental studies were included in this study. There was no time limitation in the search. After this step, the duplicate studies were excluded from the study pool. Then, those studies were named to be identical. There were a total of 15 studies found from ERIC database and 67 studies found in Web of Science database.

\section{Selection of the Studies}

There were inclusion and exclusion criteria in this particular study, which are provided below:

- The studies must focus on parental mediation.

- The studies must include parental mediation strategies.

- The studies must examine the factors that affect parental mediation strategies.

The studies were selected through a path provided in Figure 1. The review of the studies was completed in November 2020.

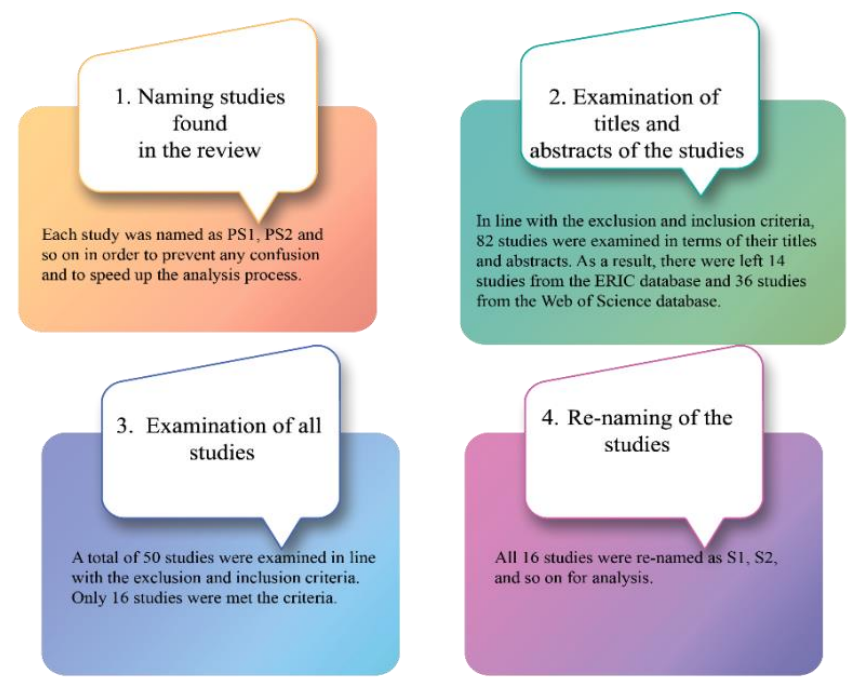

Figure 1. Selection of studies 
Analysis of the Studies

Coding of the studies and their analysis were completed through three steps, which are provided below.

(1) In order to determine the factors, the studies were reviewed and draft version of the codes (factors) was created (Fig.2). These codes were used throughout the analysis and updated as needed.

(2) The findings of the studies were analyzed based on the codes.

(3) After the analysis process, the codes and analyses were reviewed and finalized

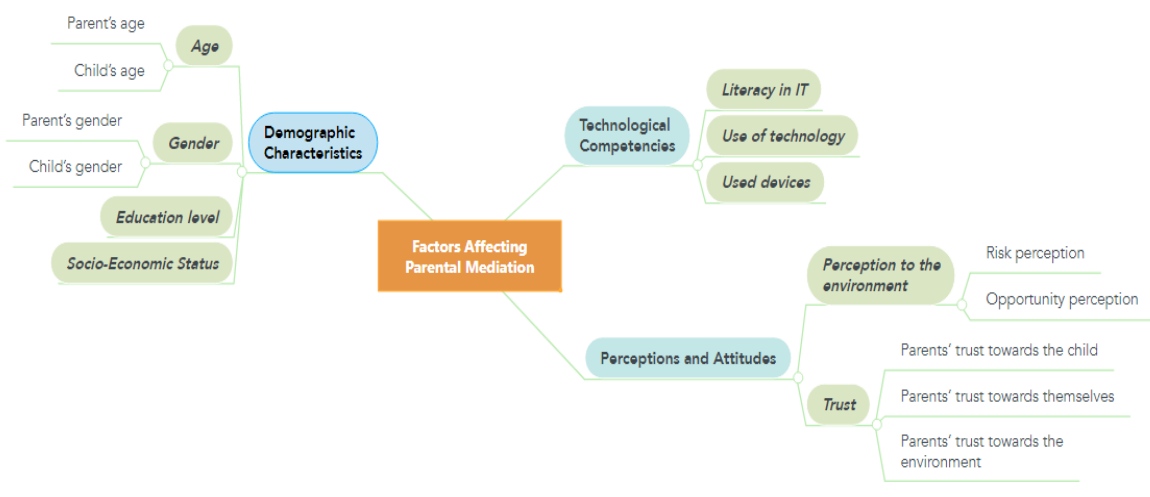

Figure 2. Factors affecting parental mediation

\section{Validity and Reliability}

Yıldırım and Şimşek (2018) stated that researchers should take precautions (validity) in order to reach accurate information and ensure that other researchers evaluate the data and analysis procedure clearly and in detail (reliability). Also, Büyüköztürk and colleagues (2018) indicated that the detailed and clear reporting of the study is of great importance in terms of validity and reliability so that the study can be replicated. On the other hand, Lincoln and Guba (1985) preferred credibility rather than internal validity, transferability rather than external validity, dependability rather than internal reliability, and conformability rather than external reliability.

In qualitative studies, one way to increase credibility is to obtain expert examination (Başkale, 2016), which refers to examination of a study in various dimensions by experts who are knowledgeable about the research subject and qualitative research methods (Creswell, 2003). In this context, three experts reviewed the keywords and codes (factors) and revisions were made when necessary. In addition, more comprehensive data was obtained by reaching 
out most of the studies on digital parental mediation strategies through ERIC and Web of Science databases. In order to achieve transferability, the participant selection, their demographic information, and data collection process should be explained in detail (ShartsHopko, 2002), which was taken into account in this particular study.

Dependability implies that the findings are based on the data and are not affected by researchers' perspective (Shenton, 2004). In this context, as Lincoln and Guba (1985) suggested, the data collection and analysis procedures and determination of codes and themes were explained in detail and the findings were supported with direct quotes from the studies. Yıldırım and Şimşek (2018) stated that full objectivity is not possible in qualitative studies and that a study in which the researcher has no influence cannot be mentioned. Therefore, Guba and Lincoln suggested the term conformability rather than objectivity. For this reason, it is expected that the data and the results in qualitative studies will be confirmed. In this study, the data collection, analysis, and interpretation procedures of this study were examined by more than one researcher. Specifically, while the findings were recorded, the codes (factors) were reviewed repeatedly. In addition, the studies were numbered to ensure the verification of the analysis results.

\section{Findings}

It was determined that demographic characteristics including age, gender, education, and socio-economic status were the factors mainly used in the studies examined within the scope of the study. In addition, digital literacy and parental perceptions and attitudes were the other factors addressed in some studies. Those factors affecting parental mediation are shown in Table 1.

Table 1. Determined factors affecting parental mediation

\begin{tabular}{ll|l}
\hline Factors & Studies focused on the factors \\
\hline $\begin{array}{l}\text { Demographic } \\
\text { characteristics }\end{array}$ & Age & $\mathrm{S} 1, \mathrm{~S} 2, \mathrm{~S} 3, \mathrm{~S} 9, \mathrm{~S} 12, \mathrm{~S} 13, \mathrm{~S} 14, \mathrm{~S} 15, \mathrm{~S} 16$ \\
\cline { 2 - 3 } & Gender & $\mathrm{S} 2, \mathrm{~S} 7, \mathrm{~S} 12, \mathrm{~S} 14, \mathrm{~S} 16$ \\
\cline { 2 - 3 } & Education level & $\mathrm{S} 2, \mathrm{~S} 5$ \\
\cline { 2 - 3 } & Socio-economic status & $\mathrm{S} 4, \mathrm{~S} 6, \mathrm{~S} 7, \mathrm{~S} 13$ \\
\hline Use of Technology & $\mathrm{S} 4, \mathrm{~S} 6, \mathrm{~S} 7, \mathrm{~S} 9, \mathrm{~S} 10, \mathrm{~S} 15$ \\
\hline Perceptions and Attitudes & $\mathrm{S} 1, \mathrm{~S} 2, \mathrm{~S} 3, \mathrm{~S} 7, \mathrm{~S} 10, \mathrm{~S} 11, \mathrm{~S} 13, \mathrm{~S} 14, \mathrm{~S} 15$ \\
\hline
\end{tabular}




\section{Demographic Characteristics}

The examined studies focused on age, gender, education level, and socio-economic status as factors affecting parental mediation.

Age

Parents' and child's age were the two factors that were considered in the studies as a variable affecting parental mediation. While age refers to the change in needs, perceptions, and developmental stages for children, it refers to the ease of technology communication with children for parents. In this context, Talves and Kalmus (2015) (S14) stated that "Parents use more mediation for younger sons and practice more activities when they feel confident to do so." In addition, children's age is a strong determinant for all types of parental mediation strategies. Symons and colleagues (2017) (S12) discussed that parents employ less mediation strategies as their children grow older by saying that "Parental mediation was largely predicted by the child's age, but less by the child's gender and the parents' ages. In line with the expectations, all informants report less mediation as the child grows older." In another study, Zaman and colleagues (2016) (S13) stated that "educational concerns seemed to outweigh entertainment in the mediation of children of school age, with parents restricting digital media use until homework was finished, restricting technology use on weekdays, or only allowing educational media content during weekdays." In that study, the researchers also emphasized that "[parents] trust their young child(ren), consider their media preferences and uses as innocent, and believe parental mediation efforts suffice to remediate potential harmful effects. Parents do, however, anticipate more concerns as children grow older, become more digital media literate, and independent." In S14, it was stated that as parents get older, they tend to use less mediation strategies; thus, Talves and Kalmus (2015) considered parents' age as a critical determinant. A similar conclusion was observed in another study conducted by Condeza and colleagues (2019) (S2). The researchers stated that young parents use technology more often than older parents, which leads them to engage in more mediation strategies. Also, it was emphasized that the communication difference between the child and the parent decrease due to young parents' technology usage levels. 


\section{Gender}

Similar to the age factor, the gender factor were divided into two categories as parent's gender and child's gender in the examined studies. Gender affects parental mediation strategies based on the identification of gender roles in societies. In terms of children, the amount of effect and benefit from digital environments varies based on gender.

Condeza and colleagues (2019) (S2) conducted their study in Chili and their participants were mainly female. The researchers stated that since mothers follow up their children's school lives, they were the main character to determine mediation strategies. In a similar study, Symons and colleagues (2017) (S12) stated that mothers employ more mediation strategies than fathers by saying that "Differences were also found between parents, with fathers indicating less mediation as compared to mothers. This suggests that mothers' increased involvement in the child's upbringing as compared to the fathers' also applies to an increased involvement in the child's Internet use." They also reported that fathers were more tolerant than mothers. Talves and Kalmus (2015) (S14) reported the variation of mediation activities according to the roles of women and men in European countries. The rate of fathers or male caregivers in mediation activities varies significantly between countries, ranging from 16\% in Germany to $36 \%$ in Norway. Aierbe and colleagues (2019) (S16) revealed that fathers are more informative towards their children than mothers and tend to explain to them more about the functionality of video games and consoles than mothers do. Also, the researchers stated that mothers have higher tendency towards use of restrictions.

A significant difference was also observed between mothers and fathers in terms of gender of their children. Aierbe and colleagues (2019) (S16) reported that fathers who have daughters give more instructions to and play more with their children compared with fathers who have sons. On the other hand, mothers restrict their sons more than their daughters. In their study, Talves and Kalmus (2015) stated that boys and girls benefit from different types of mediation strategies:

“Parents' age is also a gender-neutral significant predictor with older parents using a smaller amount of mediation activities. With regard to several other independent variables, notable gender differences appear. In the case of boys, age matters: when sons become older, parents engage in significantly less activities of active mediation. When it comes to girls, their particular experiences come to play: parents pay more attention to active mediation, if 
their daughters have been bothered on the internet and when parents believe less in daughters' self-efficacy in coping with negative online experiences."

According to the study conducted by Aierbe and colleagues (2019) (S16), parents have more time restrictions for their sons compared with daughters. On the other hand, Symons and colleagues (2017) (S16) claimed that child's gender do not have any effect on parental mediation strategies by saying that "The amount of parental mediation did not depend on the child's gender, with a few exceptions."

\section{Educational Level}

Parents' education level is considered as a factor affecting parental mediation since it has an association with the use of information and communication technologies (ICT). Katz and colleagues (2018) (S5) concluded that as parents' education level decreases, their tendency towards employing mediation strategies also decreases: "Parents with less education were more likely to have received child tech brokering and less likely to have provided tech guidance, than those with more education." In addition, the researchers stated that children provide technological support to their parents with low educational level. Specifically, Condeza and colleagues (2019) (S2) revealed that educational level is the determinant of parents' internet usage profiles. More specifically, they stated that parents with higher education degree use ICT more than other parents with lower education degree. Nikken and Opree (2018) also emphasized the importance of educational level on the use of media technologies by saying that "Also, as expected, low educated parents were less inclined to adopt new media technologies. Adoption of new media was negatively related to perceived mediation concerns..." They also concluded that this is negatively associated with parents' perceived mediation concerns.

\section{Socio-Economic Status}

Families' socio-economic status affects the variation of tools and digital environments they use in their daily lives. The studies mainly examined the differences among families with low, medium, and high socio-economic status. Katz et al. (2018) (S5) said that "parents with lower socioeconomic status and English language proficiency are the most likely to rely on their children to broker technology and least likely to guide their children's technology use." According to the results, it was revealed that parents with low socio-economic status provided less technical support for their children. In another study, Nikken and Opree (2018) (S6) pointed out the effect of socio-economic status on digital media children interact with at 
home by saying "marital status indeed determines how media are used at home by the children, and whether concerns about children and media prevail among these parents. In same vein, a lower family income and, to a lesser extent, a lower educational level also are both associated with less confidence in applying restrictive measures among parents on their young children's media use." Brito et al. (2017) (S7) also emphasized that families with low income has fever IT devices and technological facilities. These families are not aware of the positive and negative factors in IT usage; therefore, they have less concern about and negative attitude towards their children's use of Internet and digital tools. On the other hand, the researchers stated that parents with medium or high income have higher level of concern since their children have more opportunities to deal with the Internet and technological devices.

\section{Technology Usage}

Technology usage are affected by parental factors including parents' digital literacy, Internet self-efficacy, and digital media self-efficacy. Katz and colleagues (2019) (S4) found that parents who use the Internet for longer time believe that there are opportunities for children on the Internet. In another study, Nikken and Opree (2018) (S6) emphasized that parents with high confidence with Internet usage do not struggle with mediation strategies by saying that "As we surmised, along with the child's proficiency in media use, the parent's own proficiency strongly paralleled their ease of applying mediation (H7a). In families where both parents and children have more confidence in handling the media, mediation poses less of a burden on the parent." Indeed, parents who have difficulty in adopting new media technologies have more concern for their children, which result in more restrictions for children's use of media. According to Nikken and Opree (2018) (S6), since parents with high media literacy and Internet self-efficacy are aware of advantages and disadvantages of media their children use, they play more active role in parental mediation than other parents. Brito and colleagues (2017) (S7) stated that while parents who are confident and frequently use technology do not adopt authoritative mediation strategies, middle or high income parents who have high usage of technology and are addictive adopt permissive style in their mediation behaviors. Brito and colleagues also mentioned low-income families' "laissezfaire" style of mediation by saying that "The less frequent parental style was the laissez-faire. 
The majority of the families that are driven by this parental style are of a low economic status and intense use of Technologies."

\section{Perceptions and Attitudes}

In the examination of factors affecting parental mediation strategies, parents' risk and opportunity perceptions, positive and negative attitudes, and their judgments in terms of technology were found to be taken into account in related studies. Van Petegem and colleagues (2019) (S3) discussed that parents with negative attitudes towards online games tend to use more restrictive mediation strategies as their children paly online games. The researchers said that "Higher scores for parents' degree of restrictive mediation, in turn, uniquely related to parents perceiving more interest in social play, less defiance and less problematic use among their children." In another study, Brito and colleagues (2017) (S7) mentioned different perceptions of mothers and fathers. Specifically, they stated that mothers with low technology usage and limited perceptions about technology tend to show more control over their children. On the other hand, since fathers have positive perceptions about technological devices and are active users of those devices, they tend to approve their children's use of technology and practice less control activities against their children. The researchers said that "Some parents are keen to accompany their children when they use the internet fearing that they have access to inappropriate content, directing them to other activities that do not involve electronics, as in going outdoors, be it playing in a garden or doing sports."

Smahelova and colleagues (2017) (S10), on the other hand, posited that parental mediation strategies are associated with general rules and beliefs rather than risks and opportunities. In their study, the researchers concluded that when parents perceive their children as competent Internet user, they tend to support their children to use technology for a longer time and without constant supervision. On the other hand, they employ restriction strategies for children with less competence. In addition, Zaman and colleagues (2016) (S13) stated that parents' judgment about usability of devices and children's developmental abilities have effects on their mediation strategies. Aierbe and colleagues (2019) (S16) stated that while some parents are concerned about their children's early access to devices and content that are becoming increasingly difficult to control, some parents question the 
effectiveness of their mediation strategies and, as a result, they prefer setting up rules rather than employing restrictions.

\section{Discussion and Conclusion}

This study aims to systematically examine the studies in the literature to find out the factors that affect parental mediation strategies. A total of 16 studies were reviewed. The analysis of the studies revealed that parental mediation is affected by demographic characteristics (age, gender, education level, and socio-economic status), use of technology, and parents' perceptions and attitudes. Among those three factors, demographic characteristics come to the fore. The age factor, among the demographic factors, refers to parent's and child's age. Specifically, children's age affects parents' mediation strategies (Condeza et al., 2019). According to the studies, parents considered their children's use of technology as an innocent action; thus, they tend to protect them from harmful content (Zaman et al., 2016). Also, as children get older, their competencies in technology use increase, which results in changes in parents' mediation strategies. Parents who prefer to employ less restrictive strategies as the growth of their children experience more anxiety due to the lower number of strategies and flexibility in those strategies (Talves \& Kalmus, 2015). The studies examining mediation strategies of parents with children of different age groups revealed changes in children's desires and abilities and parents' behaviors depending on age (Ramos-Soler et al., 2018). Specifically, the researchers stated that parents change their attitudes, behaviors, and mediation strategies due to the change in risks and opportunities for children with time. A similar conclusion was found in studies conducted by Daneels and Vanwynsberghe (2017) and Symons et al. (2017). According to Symons et al. (2017), it is uncertain that the change in parents is because of the change in skills of children or the decrease in children's need of parents. Nevski and Siibak (2016) stated that parents tend to supervise their children more as children grow up since children's technological skills advance and the use of technological devices increases. Indeed, young children need more protection of and support from their parents (Zaman et al., 2016). In addition, as children grow up and gain more autonomy, they may face more threats in online environments, which result in parents to employ more restrictive mediation strategies (Nikken \& Jansz, 2014). With age, children need less supervision of parents but this cause more concern in parents. On the other hand, parents' age is also an important factor since it is easier for 
young parents to control the risks and opportunities that their children will face due to parents' duration of technology use and skills that develop accordingly. Condeza et al. (2019) also reported that since young parents have more digital skills, they support their children to use technology. This implies an effect of parents' digital skills on the association between parents' age and their mediation strategies.

According to the studies examined, another factor that affects parental mediation strategies is gender of parent and child. Responsibilities imposed by the society and culture in which parents live play an active role in terms of parents' gender, which directly influences the rate of being affected by and benefiting from the Internet and technological tools in children. Talves and Kalmus (2015) stated that geographical responsibilities change gender roles. Parental mediation strategies also vary when both parents work and different responsibilities are given to each gender. When mothers are considered as caregivers of children, then, they take an active role in determining mediation strategies (Condeza et al., 2019; Symons et al., 2017). This may be interpreted that fathers take less responsibility on parental mediation. Specifically, Talves and Kalmus (2015) found that in European countries parental mediation activities vary depending on the responsibilities of males and females. The same study also reported that different mediation strategies are administered to sons and daughters. This may be due to parents' risk and opportunity perceptions in terms of their children's gender. Specifically, parents employ more mediation strategies to their daughters since they believe less in their daughters' self-efficacy in dealing with online risks (Talves \& Kalmus, 2015). On the other hand, they use restrictive mediation strategies against their sons (Aierbe et al., 2019). In conclusion, the differences in mediation strategies due to children's gender are due to several factors including online opportunities (Cabello-Hutt et al., 2018), children's age, parents' media perceptions (Daneels \& Vanwynsberghe, 2017), and children's developmental needs (Symons et al., 2017) and these factors are closely related to the roles assigned to gender by culture and society. These results increase the need of crossnational studies to determine cultural differences in parental mediation strategies.

Parents' educational level influences their digital environments, perceptions towards digital tools, and skills since education provides self-confidence and a flexible perspective for individuals. Nikken and Haan (2015) mentioned the tendency of parents with higher education towards conducting research in case of any technology-related problems and seeking advice from others who have the same experience. This causes differences in their 
mediation strategies compared with the mediation strategies that parents with lower education employ. Only a few of the studies focused on the association between parents' education level and their mediation strategies. The existing studies revealed that education level affects parental mediation strategies by influencing the technological tools they use, internet access types, tendency towards research (Darga, 2021; Katz et al., 2019), the number of devices at home, the amount of Internet access, communication among family members (Cabello-Hutt et al., 2018), their perceptions towards problems they encounter, and their communication with other parents (Nikken ve de Haan, 2015). Also, Tennakoon and colleagues (2018) stated that education level and income are the predictors of parental mediation strategies by influencing other factors. Therefore, it may be concluded that rather than a direct effect, parents' education level indirectly influence parental mediation in technology use of their children.

Another factor discussed in the studies is family income. The studies reported that income influences parental mediation preferences in terms of the devices and applications parents use and digital opportunities they have (Brito et al., 2017; Darga, 2021; Zaman et al., 2016). Specifically, Brito and colleagues (2017) stated that parents with low-income own less ICT devices and technological facilities, which leads them to have less concern and negative attitudes towards their children's use of Internet and technological devices. On the other hand, parents with medium- or high-income have more concerns since they have more technological devices and facilities at home. Although studies conducted in previous years reported a direct effect of family income on parental mediation (Padilla-Walker et al., 2012), recent studies revealed its indirect effect due to the opportunity to purchase more technological devices (Katz et al., 2018) and the opportunities to be offered to the child (Brito et al., 2017) with higher income. Also, Nikken and Opree (2018) stated that parents' educational level and income influence children's interaction with digital media at home and their digital skills. Therefore, according to the findings of the studies examined, it is concluded that family income has an indirect effect on parental mediation preferences.

Another factor discussed in the studies is use of technology. Specifically, parents' media literacy and Internet and digital media self-efficacy are considered together in the studies. The results revealed that parental mediation preferences are affected by parents' use of technology (Katz et al., 2019), media literacy, and Internet self-efficacy (Nikken \& Opree, 2018; Brito et al., 2017; Nikken \& Jansz, 2014). Rodríguez-de-Dios and colleagues (2018) and 
Bartau-Rojas and colleagues (2018) stated that guidance of parents with high level of media literacy is more supportive and less restrictive than that of parents with low level of media literacy. Since parents with high level of media literacy and Internet self-efficacy are more aware of the benefits and harms of media tools, they employ different mediation strategies compared with the other parents with low level of media literacy and Internet self-efficacy. A high level of media literacy enables parents to be self-confidence in terms of technology, to predict risks their children may encounter, and to determine coping strategies in case of any threat. On the other hand, parents who are doubtful about their digital skills display a more restrictive attitude (Nikken \& Opree, 2018). As parents' technological skills increase, they employ more mediation (Livingstone et al., 2017).

The studies reported that parents' risk and opportunity perceptions, positive and negative attitudes, and parental prejudice affect parental mediation strategies. Specifically, parents' negative attitudes towards online games (Condeza et al., 2019; Van Petegem et al., 2019) cause them to consider their children more competent than themselves (Smahelova et al., 2017; Zaman et al., 2016), to believe that the content is inappropriate for children and to have anxiety (Smahelova et al., 2017; Condeza et al., 2019), which result in changes in their mediation preferences. Also, Smahelova et al. (2017) put strong emphasis on general rules and perceptions rather than risks and opportunities. Similarly, Dias and Brito (2020) revealed that parents' perceptions also directly influence their mediation strategies. Therefore, parental perceptions influence their anxiety levels, which, in turn, affect their mediation preferences.

The studies examined disclose that parental mediation is a process management that is affected by various factors including parents' and children's age and gender, educational level, income, use of technology, and attitude and perceptions towards technology. However, these factors were considered interconnected in the studies. It is difficult to examine and to define parental mediation strategies through the factors that influence parents since those factors are correlated. Therefore, the studies mainly conducted to anticipate and understand parental mediation strategies.

\section{Limitations and Recommendation}

This study has some limitations which need to be considered in the interpretation of the findings. This study is limited to only 16 studies focused on parental mediation strategies 
and the factors affecting those strategies. These studies were obtained through Web of Science and ERIC databases. First, their titles and abstracts were examined. Then, the studies were examined as a whole. However, some studies were not open-access; therefore, the researchers were unable to review those studies. Second, this study examined the studies conducted in different cultures and societies. However, these studies are limited in terms of explaining the effects of cultural and social factors on parental mediation, which increases the need of more studies to determine the effects of those factors.

\section{Recommendation for Researchers}

Researchers may consider to extent of the study in the future studies. Second, the examined studies revealed that the same effects and changes in parents' mediation preferences were due to different factors, which implies a need for more experimental studies. Third, the studies reported that the factors affecting mediation preferences were variables and all of them were associated. Future studies must examine the association between those factors to identify to what extent each factor has influence on each other in terms of parental mediation preferences. Parental mediation is critical in order to protect values of the society, to develop them in a health way, and to transform them to future generations. Therefore, future research must focus on the factors affecting parents' mediation

preferences. Specifically, since the age factor influences mediation strategies, its' association with digital skills may be examined through experimental studies, surveys, correlational and regression studies.

\section{Recommendations for Practitioners}

Parent education programs may be planned by analyzing the family structure in societies by taking into account parents' age, education level, and income. Practitioners and stakeholders may design family programs to advance parents' technology use, which may increase their awareness towards technology and to advance their mediation strategies. Such programs may also encourage parents to discuss technology-related problems they encounter with the other parents.

\section{Acknowledgement}

The data used in this study does not require the approval of Institutional Ethical Review Board. 
Author Contribution Statement

Rabia ÜSTÜNDAĞ ALKAN: Conceptualization, methodology, implementation, consultancy and control preliminary draft writing and editing.

Alper ASLAN: Conceptualization, methodology, implementation, data analysis, reviewwriting and editing.

Yiğit Emrah TURGUT: Conceptualization, methodology, implementation, data analysis, review-writing and editing.

Engin KURŞUN: Conceptualization, methodology, implementation, consultancy and control.

\section{References}

Aierbe, A., Oregui, E., \& Bartau, I. (2019). Video games, parental mediation and gender socialization. Digital Education Review, 36, 100-116.

Aspfors, J., \& Fransson, G. (2015). Research on mentor education for mentors of newly qualified teachers: A qualitative meta-synthesis.Teaching and Teacher Education, 48, 7586. https://doi.org/10.1016/j.tate.2015.02.004

Bartau-Rojas, I., Aierbe-Barandiaran, A., \& Oregui-González, E. (2018). Parental mediation of the internet use of primary students: Beliefs, strategies and difficulties. Comunicar. Media Education Research Journal, 26(1), 71-79.

Başkale, H. (2016). Nitel araştırmalarda geçerlik, güvenirlik ve örneklem büyüklügünün belirlenmesi [Determination of validity, reliability and sample size in qualitative studies]. Dokuz Eylul University Faculty of Nursing Electronic Journal, 9(1), 23-28.

Brito, R., Francisco, R., Dias, P., \& Chaudron, S. (2017). Family dynamics in digital homes: The role played by parental mediation in young children's digital practices around 14 European countries. Contemporary Family Therapy, 39(4), 271-280.

Büyüköztürk, Ş., Kılıç Çakmak, E., Akgün, Ö. E., Karadeniz, Ş., \& Demirel, F., (2018). Scientific research method 24th edition). Pegem Publication.

Cabello-Hutt, T., Cabello, P., \& Claro, M. (2018). Online opportunities and risks for children and adolescents: The role of digital skills, age, gender and parental mediation in Brazil. New Media \& Society, 20(7), 2411-2431.

Chen, W., Li, D., Bao, Z., Yan, Y., \& Zhou, Z. (2015). The impact of parent-child attachment on adolescent problematic Internet use: A moderated mediation model. Acta Psychologica Sinica, 47(5), 611-623. https://doi.org/10.3724/SP.J.1041.2015.00611

Clark, L. S. (2011). Parental mediation theory for the digital age. Communication Theory, 21(4), 323-343. https://doi.org/10.1111/j.1468-2885.2011.01391.x

Condeza, R., Herrada-Hidalgo, N., \& Barros-Friz, C. (2019). New parental mediation roles: parents' perceptions of their children's relationship with multiple screens. El Profesional de la Información (EPI), 28(4), 1699-2407. 
Coyne, S. M., Radesky, J., Collier, K. M., Gentile, D. A., Linder, J. R., Nathanson, A. I., Rasmussen, E. E., Reich, S. M., \& Rogers, J. (2017). Parenting and digital media. Pediatrics, 140(2), 112-116. https://doi.org/10.1542/peds.2016-1758N

Creswell, J. W. (2003). Research design: qualitative, quantitative and mixed methods approaches. CA: Sage Publications.

Daneels, R., \& Vanwynsberghe, H. (2017). Mediating social media use: connecting parents mediation strategies and social media literacy. Cyberpsychology: Journal of Psychosocial Research on Cyberpspace.-Brno, 11(3), 5. https://doi.org/10.5817/CP2017-3-5

Darga, H. (2021). Anasınıfına devam eden 5-6 yaş grubu çocukların evlerinde oynadıkları dijital oyunların ve ebeveynlerin davranışlarının belirlenmesi [Digital games played at home by 5-6 year old children attending kindergarten and determining parents' behaviors] Journal of Computer and Education Research, 9 (17), 447-479. DOI: $10.18009 /$ jcer.876987.

Dias, P., \& Brito, R. (2020). How families with young children are solving the dilemma between privacy and protection by building trust-A portrait from Portugal. Journal of Children and Media, 14(1), 56-73. https://doi.org/10.1080/17482798.2019.1694552

İnan-Kaya, G., Mutlu-Bayraktar, D., \& Yılmaz, Ö. (2018). Digital parenting attitude scale: validity and reliability study. Mehmet Akif Ersoy University Faculty of Education Journal, 46, 149-173. https://doi.org/10.21764/maeuefd.390626

Katz, V. S., Moran, M. B., \& Gonzalez, C. (2018). Connecting with technology in lowerincome US families. New Media \& Society, 20(7), 2509-2533.

Katz, V. S., Moran, M. B., \& Ognyanova, K. (2019). Contextualizing connectivity: how internet connection type and parental factors influence technology use among lowerincome children. Information, Communication \& Society, 22(3), 313-335.

Lincoln, Y. S., \& Guba, E. G. (1985). Naturalistic inquiry. Beverly Hills. Sage.

Livingstone, S., \& Helsper, E. J. (2008). Parental mediation of children's internet use. Journal of Broadcasting \& Electronic Media, 52(4), 581-599.

Livingstone, S., Ólafsson, K., Helsper, E. J., Lupiáñez-Villanueva, F., Veltri, G. A., \& Folkvord, F. (2017). Maximizing opportunities and minimizing risks for children online: The role of digital skills in emerging strategies of parental mediation. Journal of Communication, 67(1), 82-105. https://doi.org/10.1111/jcom.12277

Nathanson, A. I. (2015). Media and the family: Reflections and future directions. Journal of Children and Media, 9(1), 133-139. https://doi.org/10.1080/17482798.2015.997145

Nevski, E., \& Siibak, A. (2016). The role of parents and parental mediation on 0-3-year olds' digital play with smart devices: Estonian parents' attitudes and practices. Early Years, 36(3), 227-241. https://doi.org/10.1080/09575146.2016.1161601

Nikken, P., \& de Haan, J. (2015). Guiding young children's internet use at home: Problems that parents experience in their parental mediation and the need for parenting support. Cyberpsychology: Journal of Psychosocial Research on Cyberspace, 9(1). https://doi.org/10.5817/CP2015-1-3 
Nikken, P., \& Jansz, J. (2014). Developing scales to measure parental mediation of young children's internet use. Learning, Media and Technology, 39(2), 250-266. https://doi.org/10.1080/17439884.2013.782038

Nikken, P., \& Opree, S. J. (2018). Guiding young children's digital media use: SES-differences in mediation concerns and competence. Journal of Child and Family Studies, 27(6), 18441857. https://doi.org/10.1007/s10826-018-1018-3

Padilla-Walker, L. M., Coyne, S. M., Fraser, A. M., Dyer, W. J., \& Yorgason, J. B. (2012). Parents and adolescents growing up in the digital age: Latent growth curve analysis of proactive media monitoring. Journal of Adolescence, 35(5), 1153-1165.

Polat, S., \& Ay, O. (2016). Meta-Sentez: Kavramsal bir çözümleme [Meta-synthesis: A conceptual analysis. Journal of Qualitative Research in Education, 4(2), 52-64.

Ramos-Soler, I., López-Sánchez, C., \& Torrecillas-Lacave, T. (2018). Online risk perception in young people and its effects on digital behaviour. Comunicar Media Education Research Journal, 26(2), 71-79. https://www.scipedia.com/public/Ramos-Soler_et_al_2018a

Rodríguez-de-Dios, I., van Oosten, J. M., \& Igartua, J. J. (2018). A study of the relationship between parental mediation and adolescents' digital skills, online risks and online opportunities. Computers in Human Behavior, 82, 186-198.

Sandelowski, M., Docherty, S., \& Emden, C. (1997). Qualitative metasynthesis: Issues and techniques. Research in Nursing \& Health, 20(4), 365-371.

Sharts-Hopko, N. C. (2002). Assessing rigor in qualitative research. Journal of the Association of Nurses in Aids Care, 13(4), 84-86. https://doi.org/10.1016/S1055-3290(06)60374-9

Shenton, A. K. (2004). Strategies for ensuring trustworthiness in qualitative research projects. Education for Information, 22(2), 63-75. https://doi.org/10.3233/EFI-2004-22201

Smahel, D., \& Wright, M. F. (2014). The meaning of online problematic situations for children: results of qualitative cross-cultural investigation in nine European countries. London: EU Kids Online, LSE.

Smahelova, M., Juhová, D., Cermak, I., \& Smahel, D. (2017). Mediation of young children's digital technology use: The parents' perspective. Cyberpsychology: Journal of Psychosocial Research on Cyberspace, 11(3), 4. https://doi.org/10.5817/CP2017-3-4

Symons, K., Ponnet, K., Emmery, K., Walrave, M., \& Heirman, W. (2017). A factorial validation of parental mediation strategies with regard to internet use. Psychologica Belgica, 57(2), 93-111. http://doi.org/10.5334/pb.372

Talves, K., \& Kalmus, V. (2015). Gendered mediation of children's internet use: A keyhole for looking into changing socialization practices. Cyberpsychology: Journal of Psychosocial Research on Cyberspace, 9(1), 4. https://doi.org/10.5817/CP2015-1-4

Tennakoon, H., Saridakis, G., \& Mohammed, A. M. (2018). Child online safety and parental intervention: a study of Sri Lankan internet users. Information Technology \& People, 31(3), 770-790. https://doi.org/10.1108/ITP-09-2016-0213

Van Kruistum, C., \& Van Steensel, R. (2017). The tacit dimension of parental mediation. Cyberpsychology, 11(3). https://doi.org/10.5817/CP2017-3-3 
Van Petegem, S., de Ferrerre, E., Soenens, B., van Rooij, A. J., \& Van Looy, J. (2019). Parents' degree and style of restrictive mediation of young children's digital gaming: Associations with parental attitudes and perceived child adjustment. Journal of Child and Family Studies, 28(5), 1379-1391. https://doi.org/10.1007/s10826-019-01368-x

Yıldırım, A., \& Şimşek, H. (2018). Qualitative research methods in the social sciences. (11. Edition). Seçkin Yayıncılık.

Yildırım, Y. (2018). The bedside book of 21st century parents is raising children in digital culture. (1. Edition). YER: Nisan Publication.

Young, R., \& Tully, M. (2019). 'Nobody wants the parents involved': Social norms in parent and adolescent responses to cyberbullying. Journal of Youth Studies, 22(6), 856-872

Zaman, B., Nouwen, M., Vanattenhoven, J., De Ferrerre, E., \& Looy, J. V. (2016). A qualitative inquiry into the contextualized parental mediation practices of young children's digital media use at home. Journal of Broadcasting $\mathcal{E}$ Electronic Media, 60(1), 1-22.

Zimmer, L. (2006). Qualitative meta-synthesis: a question of dialoguing with texts. Journal of Advanced Nursing, 53(3), 311-318. https://doi.org/10.1111/j.1365-2648.2006.03721.x 
Addition

\begin{tabular}{|c|c|}
\hline S1 & $\begin{array}{l}\text { Dias, P., \& Brito, R. (2020). How families with young children are solving the dilemma between } \\
\text { privacy and protection by building trust-A portrait from Portugal. Journal of Children and } \\
\text { Media, 14(1), 56-73. https://doi.org/10.1080/17482798.2019.1694552 }\end{array}$ \\
\hline S2: & $\begin{array}{l}\text { Condeza, R., Herrada-Hidalgo, N., \& Barros-Friz, C. (2019). Nuevos roles parentales de mediación: } \\
\text { percepciones de los padres sobre la relación de sus hijos con múltiples pantallas. El Profesional } \\
\text { de la Información (EPI), 28(4), 1699-2407. https://doi.org/10.3145/EPI }\end{array}$ \\
\hline S3: & $\begin{array}{l}\text { Van Petegem, S., de Ferrerre, E., Soenens, B., van Rooij, A. J., \& Van Looy, J. (2019). Parents' degree } \\
\text { and style of restrictive mediation of young children's digital gaming: Associations with } \\
\text { parental attitudes and perceived child adjustment. Journal of Child and Family Studies, 28(5), } \\
\text { 1379-1391. https://doi.org/10.1007/s10826-019-01368-x }\end{array}$ \\
\hline \multirow[t]{2}{*}{ S4: } & $\begin{array}{l}\text { Katz, V. S., Moran, M. B., \& Ognyanova, K. (2019). Contextualizing connectivity: how internet } \\
\text { connection type and parental factors influence technology use among lower-income children. }\end{array}$ \\
\hline & $\begin{array}{lcrrr}\begin{array}{l}\text { Information, } \\
\text { https://doi.org/10.1080/1369118X.2017.1379551 }\end{array} & \text { Society, } & \text { 22(3), } & \text { 313-335. } \\
\end{array}$ \\
\hline S5: & $\begin{array}{l}\text { Katz, V. S., Moran, M. B., \& Gonzalez, C. (2018). Connecting with technology in lower-income US } \\
\text { families. New Media \& Society, 20(7), 2509-2533. https://doi.org/10.1177/1461444817726319 }\end{array}$ \\
\hline S6: & $\begin{array}{l}\text { Nikken, P., \& Opree, S. J. (2018). Guiding young children's digital media use: SES-differences in } \\
\text { mediation concerns and competence. Journal of Child and Family Studies, 27(6), 1844-1857. } \\
\text { https://doi.org/10.1007/s10826-018-1018-3 }\end{array}$ \\
\hline S7: & $\begin{array}{l}\text { Brito, R., Francisco, R., Dias, P., \& Chaudron, S. (2017). Family dynamics in digital homes: The role } \\
\text { played by parental mediation in young children's digital practices around } 14 \text { European } \\
\text { countries. Contemporary Family Therapy, 39(4), 271-280. https://doi.org/10.1007/s10591-017-9431- } \\
0\end{array}$ \\
\hline
\end{tabular}

S8: $\quad$ Sánchez-Valle, M., de-Frutos-Torres, B., \& Vázquez-Barrio, T. (2017). Parent's influence on acquiring critical internet skills. Comunicar. Media Education Research Journal, 25(2) 103-111. https://www.scipedia.com/public/Sanchez-Valle_et_al_2017a

S9: $\quad$ Daneels, R., \& Vanwynsberghe, H. (2017). Mediating social media use: connecting parents mediation strategies and social media literacy. Cyberpsychology: Journal of Psychosocial Research on Cyberpspace.-Brno, 11(3), 5. https://doi.org/10.5817/CP2017-3-5

S10: Smahelova, M., Juhová, D., Cermak, I., \& Smahel, D. (2017). Mediation of young children's digital technology use: The parents' perspective. Cyberpsychology: Journal of Psychosocial Research on Cyberspace, 11(3), 4. https://doi.org/10.5817/CP2017-3-4

S11: Van Kruistum, C., \& Van Steensel, R. (2017). The tacit dimension of parental mediation. Cyberpsychology, 11(3 Special Issue). https://doi.org/10.5817/CP2017-3-3

S12: $\quad$ Symons, K., Ponnet, K., Emmery, K., Walrave, M., \& Heirman, W. (2017). A factorial validation of parental mediation strategies with regard to internet use. Psychologica Belgica, 57(2), 93-111. http://doi.org/10.5334/pb.372

S13: Zaman, B., Nouwen, M., Vanattenhoven, J., De Ferrerre, E., \& Looy, J. V. (2016). A qualitative inquiry into the contextualized parental mediation practices of young children's digital media use at home. Journal of Broadcasting $\mathcal{E}$ Electronic Media,60(1), 1-22. https://doi.org/10.1080/08838151.2015.1127240

S14: $\quad$ Talves, K., \& Kalmus, V. (2015). Gendered mediation of children's internet use: A keyhole for looking into changing socialization practices. Cyberpsychology: Journal of Psychosocial Research on Cyberspace, 9(1), 4. https://doi.org/10.5817/CP2015-1-4

S15: Nikken, P., \& Jansz, J. (2014). Developing scales to measure parental mediation of young children's internet use. Learning, Media and Technology, 39(2), 250-266. https://doi.org/10.1080/17439884.2013.782038

S16: Aierbe, A., Oregui, E., \& Bartau, I. (2019). Video games, parental mediation and gender socialization. Digital Education Review, (36), 100-116. http://hdl.handle.net/10810/41961

Copyright C JCER

JCER's Publication Ethics and Publication Malpractice Statement are based, in large part, on the guidelines and standards

developed by the Committee on Publication Ethics (COPE). This article is available under Creative Commons CC-BY 4.0 license

(https://creativecommons.org/licenses/by/4.0/) 